\title{
Lobatamunsolides A-C, Norlignans from the Roots of Pueraria lobata and their Nitric Oxide Inhibitory Activities in Macrophages
}

\author{
Mun Seok Jo ${ }^{1}$, Jae Sik Yu ${ }^{1}$, Joo Chan Lee ${ }^{1}$, Seoyoung Lee ${ }^{2}$, Young-Chang Cho ${ }^{2}$, \\ Hyun-Ju Park ${ }^{1}$ (D) and Ki Hyun Kim ${ }^{1, *(D)}$ \\ 1 School of Pharmacy, Sungkyunkwan University, Suwon 16419, Korea; anstjr920827@gmail.com (M.S.J.); \\ jsyu@bu.edu (J.S.Y.); leejc3004@gmail.com (J.C.L.); hyunju85@skku.edu (H.-J.P.) \\ 2 College of Pharmacy, Chonnam National University, Gwangju 61186, Korea; 96_29@naver.com (S.L.); \\ yccho@jnu.ac.kr (Y.-C.C.) \\ * Correspondence: khkim83@skku.edu; Tel.: +82-31-290-7700
}

Received: 31 October 2019; Accepted: 17 November 2019; Published: 20 November 2019

\begin{abstract}
Phytochemical investigation of the methanol (MeOH) extract of Pueraria lobata roots, known as "kudzu", combined with liquid chromatography/mass spectrometry (LC/MS)-based analysis, resulted in the identification of four norlignans (1-4), including three new norlignans, lobatamunsolides A-C (1-3), and five known isoflavonoids (5-9). The structures of the new compounds were elucidated by a combination of spectroscopic methods, including $1 \mathrm{D}$ and 2D nuclear magnetic resonance (NMR) and high resolution (HR)-electrospray ionization mass spectrometry (ESIMS), and their absolute configurations were determined by chemical reaction and quantum chemical electronic circular dichroism (ECD) calculations. The isolated compounds (1-9) were evaluated for their inhibitory effects on nitric oxide (NO) production in lipopolysaccharide (LPS)-stimulated RAW 264.7 macrophages. Compound 9 displayed the strongest NO inhibitory effect and compound $\mathbf{2}$ showed a weak effect. The potential mechanism of the effect of compound $\mathbf{9}$ was investigated by analysis of its molecular docking on the active site of inducible nitric oxide synthase (iNOS), which showed the potential interactions of compound 9 with key amino acid residues and the heme cofactor of iNOS. The mechanism as the inhibition of transcriptional iNOS protein expression was confirmed by western blotting experiments.
\end{abstract}

Keywords: Pueraria lobata; norlignan; NMR; nitric oxide; RAW 264.7

\section{Introduction}

Pueraria lobata (Willd.) Ohwi is a creeping, climbing, and trailing perennial vine belonging to the plant family Leguminosae, and is distributed in Southeast Asia, the Pacific, East Asia (Korea, China, Japan, and Russian far east), and the United States [1,2]. P. lobata, commonly known as "kudzu", has been used in Korean traditional medicine for treating headache, diarrhea, fever, and cardiovascular disease [3,4]. In particular, the root of $P$. lobata has been used as a major medicinal and food ingredient in East Asia. Starch from P. lobata root is consumed as a popular drink in Vietnam and is used in many dishes, including kuzumochi and kuzuyu, in Japan, indicating the high nutritional value of the P. lobata root [5]. Previous studies have shown that extracts of $P$. lobata roots prevent obesity, improve glucose metabolism [6], and reduce oxidative stress [7]. In addition, previous phytochemical studies on the roots of $P$. lobata have revealed that its major bioactive compounds are isoflavones such as daidzein, daidzin, puerarin, and genistein [8]. These isoflavones exhibit diverse pharmacological effects, such as anti-inflammatory, antimicrobial, antioxidant, and antidipsotropic effects $[9,10]$. The P. lobata root 
has recently become commercially available in Western dietary supplements for the treatment of menopausal symptoms, and P. lobata root isoflavones such as puerarin have shown promise as natural alternatives to hormone replacement therapy for postmenopausal symptoms, with reduced risks of cancer [11,12].

As part of ongoing projects to identify structurally and/or biologically novel compounds from natural sources [13-17], we investigated the active compounds from P. lobata root that have both estrogen-like and anti-breast cancer cell proliferative activities. We used the bioactivity-guided isolation approach employed in a recent report that demonstrated that genistein from P. lobata root has estrogen-like effects dependent on estrogen receptor (ER) pathway activation, and anti-proliferative effects mediated by the apoptosis pathway in MCF-7 breast cancer cells [18]. These findings prompted us to investigate other potential bioactive components from P. lobata roots. Chemical analysis of the methanol $(\mathrm{MeOH})$ extract of $P$. lobata root combined with liquid chromatography/mass spectrometry (LC/MS)-based analysis using an in-house ultraviolet (UV) spectra library led to the isolation and identification of four norlignans (1-4), including three new norlignans (1-3) (Figure 1), and five isoflavonoids (5-9) from the $n$-butanol-soluble fraction of the extract. The structures of the new norlignans were elucidated by a combination of 1D and 2D nuclear magnetic resonance (NMR) spectroscopic experiments, high resolution (HR)-electrospray ionization mass spectrometry (ESIMS), chemical reactions, and quantum chemical electronic circular dichroism (ECD) calculations. Furthermore, we elucidated the inhibitory effects of compounds 1-9 on nitric oxide (NO) production in lipopolysaccharide (LPS)-activated RAW 264.7 macrophages.

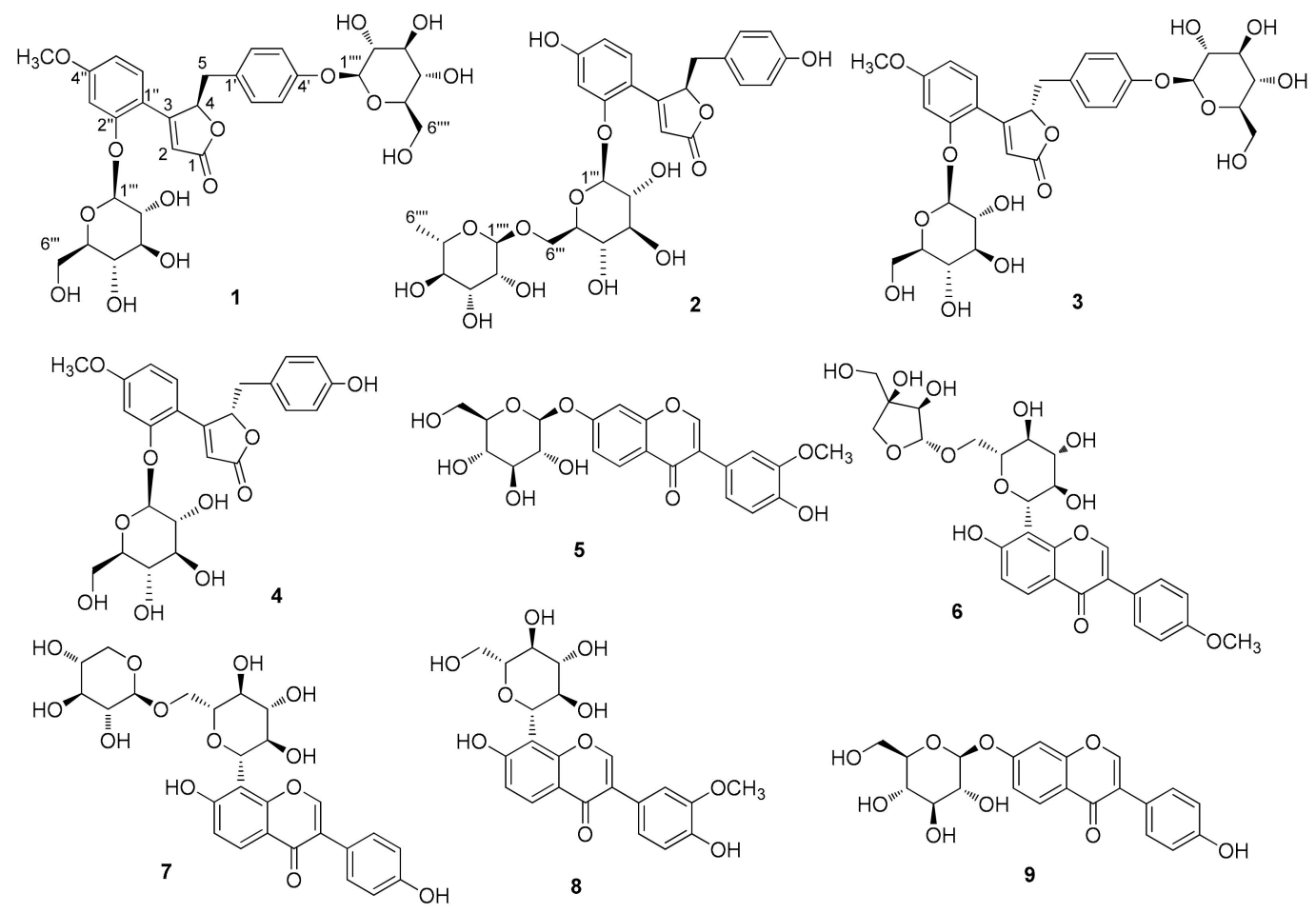

Figure 1. Structures of compounds 1-9 isolated from P. lobata roots.

\section{Materials and Methods}

\subsection{Plant Material}

P. lobata roots grown in Geochang, Gyeongnam Province, Korea in 2014 were purchased from Okchundang Co., Ltd. A sample specimen of this material (GK-14-063) was confirmed by one of the authors (K. H. Kim) and stored in the herbarium of the School of Pharmacy, Sungkyunkwan University, Suwon, Korea. 


\subsection{Extraction and Isolation}

The dried P. lobata roots $(500 \mathrm{~g})$ were extracted using $80 \% \mathrm{MeOH}(20 \mathrm{~h} \times 3)$ at room temperature. The extract was finely filtered and evaporated under reduced pressure using a rotary evaporator to obtain the $\mathrm{MeOH}$ extract (206.7 g). An in-depth description regarding the isolation of compounds from $\mathrm{MeOH}$ extract using the LC/MS guided isolation method can be found in the Supplementary Materials.

\subsubsection{Lobatamunsolide A (1)}

White, amorphous powder; $[\alpha]_{\mathrm{D}}^{25}-38.8$ (c 0.08, MeOH); UV (MeOH) $\lambda_{\max }(\log \varepsilon) 195$ (4.0), 215 (3.2), 310 (2.7) nm; ECD (MeOH) $\lambda_{\max }(\Delta \varepsilon) 228$ (-9.76), 250 (+7.01), $282(-15.76) \mathrm{nm} ; \mathrm{IR}(\mathrm{KBr}) v_{\max } 3705$, 2966, 2833, 2492, 2704, 1698, 1516, $1024 \mathrm{~cm}^{-1} ;{ }^{1} \mathrm{H}(850 \mathrm{MHz})$ and ${ }^{13} \mathrm{C}(212.5 \mathrm{MHz}) \mathrm{NMR}$ data,

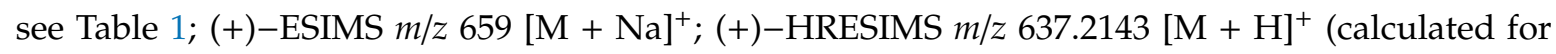
$\mathrm{C}_{30} \mathrm{H}_{37} \mathrm{O}_{15}$ 637.2132).

\subsubsection{Lobatamunsolide B (2)}

White, amorphous powder; $[\alpha]_{\mathrm{D}}^{25}+23.1$ (c 0.08, MeOH); UV (MeOH) $\lambda_{\max }(\log \varepsilon) 195$ (4.0), 215 (3.2), 310 (2.7) nm; ECD (MeOH) $\lambda_{\max }(\Delta \varepsilon) 230$ (-5.19), 254 (+8.34), 284 (-19.77) nm; IR (KBr) $v_{\max } 3705$, 3330, 2947, 2828, 2513, 2047, 1453, $1029 \mathrm{~cm}^{-1} ;{ }^{1} \mathrm{H}(850 \mathrm{MHz})$ and ${ }^{13} \mathrm{C}(212.5 \mathrm{MHz}) \mathrm{NMR}$ data,

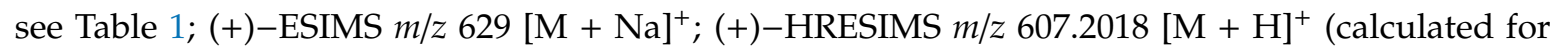
$\mathrm{C}_{29} \mathrm{H}_{35} \mathrm{O}_{14}$ 607.2027).

\subsubsection{Lobatamunsolide C (3)}

White, amorphous powder; $[\alpha]_{\mathrm{D}}^{25}-50.1$ (c 0.09, MeOH); UV (MeOH) $\lambda_{\max }(\log \varepsilon) 200$ (3.5), 215 (3.8), 310 (3.7) nm; ECD (MeOH) $\lambda_{\max }(\Delta \varepsilon) 228$ (+1.55), 247 (-27.72), 284 (+24.02) nm; IR (KBr) $v_{\max }$ $3709,3320,2940,2827,1750,1446,1127,1024 \mathrm{~cm}^{-1} ;{ }^{1} \mathrm{H}(850 \mathrm{MHz})$ and ${ }^{13} \mathrm{C}(212.5 \mathrm{MHz}) \mathrm{NMR}$ data,

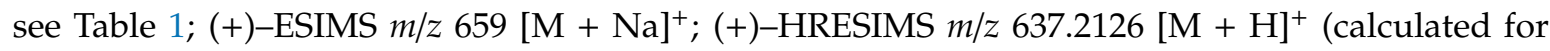
$\mathrm{C}_{30} \mathrm{H}_{37} \mathrm{O}_{15}$ 637.2132).

\subsection{Acid Hydrolysis and Determination of the Absolute Configuration of Sugar Moieties}

The absolute configuration of the sugar moieties was determined using an LC/MS-UV-based method, which is described in detail in the Supplementary Materials.

\subsection{Computational Analysis}

Conformational optimization of $\mathbf{1} \mathbf{a} / \mathbf{1} \mathbf{b}$ was carried out using computational density functional theory (DFT) calculations. The first structural energy minimization of $\mathbf{1 a} / \mathbf{1} \mathbf{b}$ was carried out using Avogadro 1.2.0 with universal force field (UFF) setting. The ground-state geometries of $\mathbf{1 a} / \mathbf{1} \mathbf{b}$ were established by Tmolex 4.3.1 with DFT settings at B3-LYP functional/M3 grid size, geometry optimization options were set at energy $10^{-6}$ hartree, gradient norm $|\mathrm{d} E / \mathrm{d} x y z|=10^{-3}$ hartree/bohr, and the basis set was def-SV(P) by default for all atoms. The details of this analysis are described in the Supplementary Materials.

\subsection{NO Production Assay}

RAW 264.7 cells $\left(6.0 \times 10^{4}\right.$ cells/well $)$ in 96 well plates were incubated overnight and then stimulated with LPS $(1 \mu \mathrm{g} / \mathrm{mL})$ after treatment with the indicated concentrations of compounds. After $100 \mu \mathrm{L}$, cultured media were transferred to a new 96 well plate, and $100 \mu \mathrm{L}$ Griess reagent (a mixture of $1 \%$ sulfanilamide in $2.5 \%$ phosphoric acid $\left(\mathrm{H}_{3} \mathrm{PO}_{4}\right)$ and $0.1 \% \mathrm{~N}-(1$-raphthyl) ethylenediamine in distilled water) was added to each well. Sodium nitrite was used to generate a standard curve. Absorbance was measured at $540 \mathrm{~nm}$ using a Synergy H1 Microplate Reader. 


\subsection{Cell Viability Assay}

Cell viability was measured using the EZ-Cytox cell viability assay kit (DAEIL lab, Seoul, Korea) according to the manufacturer's instruction. RAW 264.7 cells $\left(6.0 \times 10^{4}\right.$ cells/well) were seeded into a 96 well plate. After overnight incubation, cells were treated with different concentrations of compounds. After incubation for $24 \mathrm{~h}$, the cells were incubated for $1 \mathrm{~h}$ at $37^{\circ} \mathrm{C}$ by adding EZ-Cytox diluent. Absorbance of culture medium was measured at $450 \mathrm{~nm}$ using a Synergy H1 Microplate Reader (BioTek Instruments, Winooski, VT, USA).

\subsection{Preparation of Ligand and Receptor for Docking}

All the procedures for docking modeling were carried out using the Tripos Sybyl-X 2.1.1 (Tripos Inc, St Louis, MO, USA) molecular modeling package with a Windows 7 professional K operating system. The structure of compound 9 was sketched and saved in the MOL2 format. Sequentially, Gasteiger-Hückel charges were assigned to all the atoms. To optimize the structure, energy minimization was conducted under a standard tripos force field with convergence to maximum derivatives of $0.001 \mathrm{kcal} \mathrm{mol}^{-1} . \AA^{-1}$. As a target receptor for 9, the X-ray structure of murine iNOS in complex with the inhibitor AR-C124355 (PDB id: 3E6O) was downloaded at a resolution of $2.6 \AA$ from Protein Data Bank (https://www.rcsb.org). To prepare the receptor, all the water molecules and duplicated chains were deleted, hydrogen atoms were attached, and Amber 7 FF99 charges were assigned using the biopolymer module in the Sybyl program.

\subsection{Molecular Docking Analysis}

Flexible docking was performed using a Surflex-Dock embedded in Tripos Sybyl X 2.1.1. The active site was generated as a protomol based on a native ligand (AR-C124355) extracted from the co-crystal structure of iNOS (PDB id: 3E6O). The protomol was built using the hydrogen-containing protein mol2 file. All parameters were applied by default to the docking simulation and 50 conformers were generated for the ligand. The binding affinity $\left(-\log K_{d}\right)$ of each conformer was calculated by the Surflex-Dock scoring function, and consensus scores were obtained based on five scores (Total Score, PMF score, ChemScore, G score, D score). The best docking model was picked out considering the calculated binding affinity, consensus score $\geq 4$, and the number of intermolecular interactions.

\subsection{Western Blot Analysis}

RAW 264.7 cells $\left(2.0 \times 10^{6}\right.$ cells/well $)$ were seeded into 6 well plates and incubated overnight for adhesion. Cells were simultaneously treated with selected concentrations $(25 \mu \mathrm{M}$ and $100 \mu \mathrm{M})$ of compounds 2 and 9 and LPS $(1 \mu \mathrm{g} / \mathrm{mL})$ and incubated for $24 \mathrm{~h}$. After washing cells with ice-cold PBS, radioimmunoprecipitation assay (RIPA) buffer was applied to the cells and the supernatants obtained after centrifugation were collected as total protein lysates. The same quantities of proteins were prepared with protein sample loading buffer and subjected to SDS-PAGE. Proteins separated on the gel were transferred onto nitrocellulose (NC) membranes, which were then blocked with $5 \%$ non-fat dried milk. The membranes were incubated overnight at $4{ }^{\circ} \mathrm{C}$ with iNOS and GAPDH primary antibodies, following which secondary antibodies conjugated with HRP were applied to the membranes. Finally, the membranes were blotted with an enhanced chemiluminescence reagent, and the intensities of bands obtained were quantified using an Amersham Imager 680 (GE Healthcare, Chicago, IL, United States).

\subsection{Statistical Analysis}

Significance of the data was analyzed by employing Student's $t$-test. Results for experimental replicates ( $n=9$ for NO assay and cell viability; $n=3$ for western blotting) were compared with those for the LPS-treated control group. $p<0.05$ was considered statistically significant, and groups showing statistically significant differences are indicated with an asterisk $\left(^{*}\right)$. 


\section{Results and Discussion}

\subsection{Isolation of Compounds}

LC/MS-guided phytochemical investigation of the $\mathrm{MeOH}$ extract using series of column chromatography, such as silica gel, $\mathrm{RP}-\mathrm{C}_{18}$ silica, Sephadex LH-20, and HP-20, along with preparative and semi-preparative HPLC, were used to isolate and identify four norlignans (1-4), including three new norlignans (1-3), and five isoflavonoids (5-9) from the $n$-butanol-soluble fraction of the extract.

\subsection{Structure Elucidation of Compounds}

Compound 1 was isolated as a white amorphous powder. Its molecular formula was determined to be $\mathrm{C}_{30} \mathrm{H}_{36} \mathrm{O}_{15}$ based on the $[\mathrm{M}+\mathrm{H}]^{+}$peak at $m / z 637.2143$ (calculated for $\mathrm{C}_{30} \mathrm{H}_{37} \mathrm{O}_{15}$ 637.2132) in the positive-ion HR-ESI-MS spectrum. The IR spectrum of $\mathbf{1}$ showed absorption bands for hydroxy $\left(3356 \mathrm{~cm}^{-1}\right)$ and $\alpha, \beta$-unsaturated ketone $\left(1677 \mathrm{~cm}^{-1}\right)$ functional groups. The ${ }^{1} \mathrm{H}$ NMR spectrum of 1 (Table 1) showed signals for a proton set of 1,4-disubstituted benzene at $\delta_{\mathrm{H}} 6.89(2 \mathrm{H}, \mathrm{d}, J=8.5 \mathrm{~Hz})$ and $6.85(2 \mathrm{H}, \mathrm{d}, J=8.5 \mathrm{~Hz})$; another proton set of 1,3,4-trisubstituted benzene at $\delta_{\mathrm{H}} 7.34(1 \mathrm{H}, \mathrm{d}, J=8.5 \mathrm{~Hz})$, $6.96(1 \mathrm{H}, \mathrm{d}, J=2.5 \mathrm{~Hz})$, and $6.73(1 \mathrm{H}, \mathrm{dd}, J=8.5,2.5 \mathrm{~Hz})$; one olefinic proton at $\delta_{\mathrm{H}} 6.30(1 \mathrm{H}, \mathrm{d}, J=1.0$ $\mathrm{Hz})$; one oxygenated proton at $\delta_{\mathrm{H}} 6.07(1 \mathrm{H}, \mathrm{td}, J=4.5,1.0 \mathrm{~Hz})$; one methylene proton at $\delta_{\mathrm{H}} 3.24(1 \mathrm{H}$, $\mathrm{dd}, J=15.0,4.5 \mathrm{~Hz})$ and $2.92(1 \mathrm{H}, \mathrm{dd}, J=15.0,4.5 \mathrm{~Hz})$; one methoxy group at $\delta_{\mathrm{H}} 3.88(3 \mathrm{H}, \mathrm{s})$; as well as signals attributable to two sugar moieties, including two anomeric protons at $\delta_{\mathrm{H}} 5.12(1 \mathrm{H}, \mathrm{d}, J=7.5 \mathrm{~Hz})$ and $4.84(1 \mathrm{H}, \mathrm{d}, J=7.5 \mathrm{~Hz})$. The ${ }^{13} \mathrm{C}$ NMR data (Table 1$)$, obtained with the aid of heteronuclear single quantum coherence (HSQC) and heteronuclear multiple bond correlation (HMBC) spectra, displayed resonances of 18 carbons for aglycone, including 12 carbons of aromatic rings, $\alpha, \beta$-unsaturated ketone $\left(\delta_{C} 176.4,166.7\right.$, and 115.9$)$, one methylene $\left(\delta_{C} 38.7\right)$, one oxygenated methine $\left(\delta_{C} 84.6\right)$, and one methoxy group $\left(\delta_{C} 56.0\right)$, together with 12 carbons of two sugar groups. Detailed inspection of ${ }^{1} \mathrm{H}$ and ${ }^{13}$ C NMR data revealed that our NMR data closely coincided with those for kuzubutenolide A [19], except for the signals for an additional sugar moiety and one methoxy group. Both sugar units were determined to be glucopyranose upon comparing our values with those reported previously [19]; moreover, the coupling constant $(J=7.5 \mathrm{~Hz})$ of anomeric proton signals was indicative of the $\beta$-form of glucopyranose [20]. The locations of the two $\beta$-glucopyranosyl groups were clearly confirmed as C-2" and C-4' through HMBC correlations of the two anomeric protons with C-2" $\left(\delta_{\mathrm{C}} 158.5\right)$ and C-4' $\left(\delta_{C} 158.0\right)$, respectively (Figure 2$)$. The HMBC correlations of the methoxy group $\left(\delta_{\mathrm{H}} 3.88\right)$ with C-4" ${ }^{\prime \prime}\left(\delta_{C} 164.8\right)$ allowed us to confirm its location as C-4" (Figure 2). The gross planar structure of 1 was completely elucidated through $2 \mathrm{D}$ NMR analysis $\left({ }^{1} \mathrm{H}-{ }^{1} \mathrm{H}\right.$ correlation spectroscopy (COSY), HSQC, and HMBC) (Figure 2). The absolute configuration of sugar moieties was determined using an LC/MS-UV-based method [21-23], and acid hydrolysis of $\mathbf{1}$ was carried out to yield a glucopyranose. The absolute configuration of the sugar moieties was determined as D-glucopyranose by comparing the retention times of the thiocarbamoyl-thiazolidine derivative of their acid hydrolysates with that of the standard D-glucopyranose sample through LC/MS analysis. In order to confirm the absolute configuration, quantum chemical ECD calculations were performed by comparing the experimental ECD spectrum of $\mathbf{1}$ with the calculated ECD spectra of two possible enantiomers, $\mathbf{1 a}(4 R)$ and $\mathbf{1} \mathbf{b}$ (4S) (Figure 3). The experimental ECD data of $\mathbf{1}$ matched well with the calculated ECD data for $\mathbf{1 a .}$ Accordingly, the chemical structure of 1, including its absolute configuration, was elucidated as shown in Figure 1, and the compound was named lobatamunsolide A. 


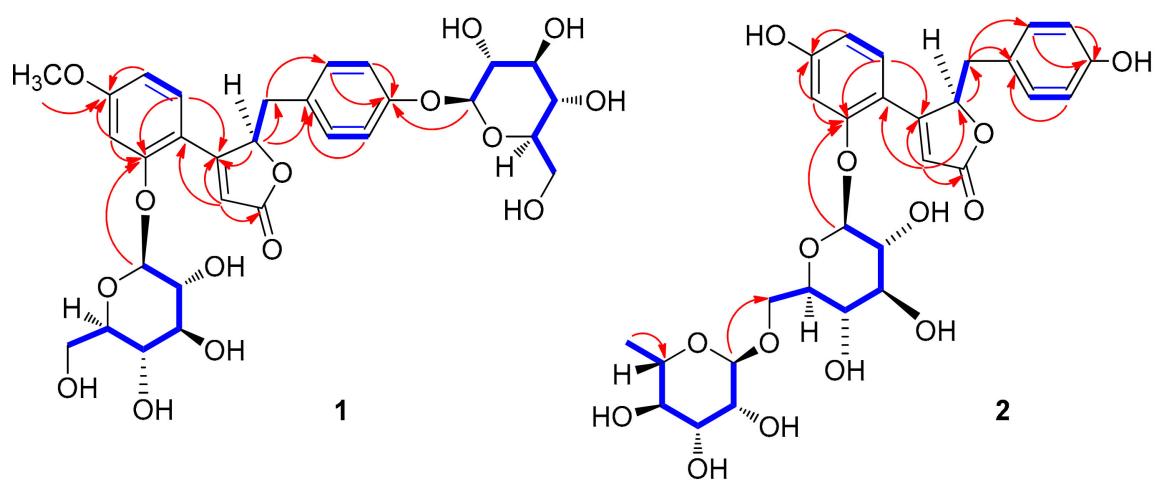

Figure 2. ${ }^{1} \mathrm{H}-{ }^{1} \mathrm{H}$ correlation spectroscopy (COSY) (blue bold lines) and key heteronuclear multiple bond correlation (HMBC) (red arrows) correlations of $\mathbf{1}$ and 2.

Table 1. ${ }^{1} \mathrm{H}$ and ${ }^{13} \mathrm{C}$ nuclear magnetic resonance (NMR) data of Compounds $1-3$ in $\mathrm{CD}_{3} \mathrm{OD}^{a}$.

\begin{tabular}{|c|c|c|c|c|c|c|c|c|c|}
\hline \multirow{2}{*}{ Position } & \multicolumn{3}{|l|}{1} & \multicolumn{3}{|l|}{2} & \multicolumn{3}{|l|}{3} \\
\hline & $\delta_{\mathrm{H}}$ & $\delta_{\mathrm{C}}$ & & $\delta_{\mathrm{H}}$ & $\delta_{\mathrm{C}}$ & & $\delta_{\mathrm{H}}$ & $\delta_{\mathrm{C}}$ & \\
\hline 1 & & 176.4 & $\mathrm{~s}$ & & 176.7 & $\mathrm{~s}$ & & 176.0 & $\mathrm{~s}$ \\
\hline 2 & $6.30 \mathrm{~d}(1.0)$ & 115.9 & d & $6.26 \mathrm{~s}$ & 114.9 & $\mathrm{~d}$ & $6.17 \mathrm{~s}$ & 114.4 & $\mathrm{~d}$ \\
\hline 3 & & 166.7 & $\mathrm{~s}$ & & 167.3 & $\mathrm{~s}$ & & 168.1 & $\mathrm{~s}$ \\
\hline 4 & $6.07 \mathrm{td}(4.5,1.0)$ & 84.6 & $\mathrm{~d}$ & $6.04 \mathrm{td}(5.0,1.0)$ & 84.9 & $\mathrm{~d}$ & $6.16 \mathrm{~m}$ & 85.5 & $\mathrm{~d}$ \\
\hline $5 a$ & $2.92 \mathrm{dd}(15.0,5.0)$ & 38.7 & $\mathrm{t}$ & $2.86 \mathrm{dd}(15.0,5.0)$ & 38.9 & $\mathrm{t}$ & $2.85 \mathrm{dd}(15.0 .6 .0)$ & 38.8 & $\mathrm{t}$ \\
\hline $5 b$ & $3.24 \mathrm{dd}(15.0,4.5)$ & & & $3.20 \mathrm{dd}(15.0,4.0)$ & & & $3.24 \mathrm{dd}(15.0,3.5)$ & & \\
\hline $1^{\prime}$ & & 129.6 & $\mathrm{~s}$ & & 126.7 & $\mathrm{~s}$ & & 130.8 & $\mathrm{~s}$ \\
\hline $2^{\prime}$ & $6.85 \mathrm{~d}(8.5)$ & 131.9 & $\mathrm{~d}$ & $6.78 \mathrm{~d}(8.5)$ & 131.9 & $\mathrm{~d}$ & $7.00 \mathrm{~d}(8.5)$ & 131.7 & $\mathrm{~d}$ \\
\hline $3^{\prime}$ & $6.89 \mathrm{~d}(8.5)$ & 117.0 & $\mathrm{~d}$ & $6.60 \mathrm{~d}(8.5)$ & 115.5 & $\mathrm{~d}$ & $6.95 \mathrm{~d}(8.5)$ & 117.1 & $\mathrm{~d}$ \\
\hline $4^{\prime}$ & & 158.0 & $\mathrm{~s}$ & & 157.0 & $\mathrm{~s}$ & & 157.9 & $\mathrm{~s}$ \\
\hline $5^{\prime}$ & $6.89 \mathrm{~d}(8.5)$ & 117.0 & d & $6.60 \mathrm{~d}(8.5)$ & 115.5 & $\mathrm{~d}$ & $6.95 \mathrm{~d}(8.5)$ & 117.1 & $\mathrm{~d}$ \\
\hline $6^{\prime}$ & $6.85 \mathrm{~d}(8.5)$ & 131.9 & $\mathrm{~d}$ & $6.78 \mathrm{~d}(8.5)$ & 131.9 & $\mathrm{~d}$ & $7.00 \mathrm{~d}(8.5)$ & 131.7 & $\mathrm{~d}$ \\
\hline $1^{\prime \prime}$ & & 113.9 & $\mathrm{~s}$ & & 113.1 & $\mathrm{~s}$ & & 113.7 & $\mathrm{~s}$ \\
\hline $2^{\prime \prime}$ & & 158.5 & $\mathrm{~s}$ & & 158.5 & $\mathrm{~s}$ & & 158.1 & $\mathrm{~s}$ \\
\hline $3^{\prime \prime}$ & $6.96 \mathrm{~d}(2.5)$ & 102.7 & $\mathrm{~d}$ & $6.77 \mathrm{~d}(2.5)$ & 104.0 & $\mathrm{~d}$ & $6.96 \mathrm{~d}(2.5)$ & 102.3 & $\mathrm{~d}$ \\
\hline $4^{\prime \prime}$ & & 164.8 & $\mathrm{~s}$ & & 163.0 & $\mathrm{~s}$ & & 165.0 & $\mathrm{~s}$ \\
\hline $5^{\prime \prime}$ & $6.73 \mathrm{dd}(8.5,2.5)$ & 109.5 & $\mathrm{~d}$ & $6.60 \mathrm{dd}(8.5,2.5)$ & 110.9 & $\mathrm{~d}$ & $6.74 \mathrm{dd}(8.5,2.5)$ & 109.9 & $\mathrm{~d}$ \\
\hline $6^{\prime \prime}$ & $7.34 \mathrm{~d}(8.5)$ & 131.8 & d & $7.26 \mathrm{~d}(8.5)$ & 132.1 & $\mathrm{~d}$ & $7.45 \mathrm{~d}(8.5)$ & 132.2 & $\mathrm{~d}$ \\
\hline $1^{\prime \prime \prime}$ & $5.12 \mathrm{~d}(7.5)$ & 101.6 & d & $5.03 \mathrm{~d}(7.5)$ & 101.6 & $\mathrm{~d}$ & $5.07 \mathrm{~d}(7.5)$ & 101.8 & $\mathrm{~d}$ \\
\hline $2^{\prime \prime \prime}$ & $3.48 \mathrm{~m}$ & 74.6 & d & $3.49 \mathrm{~m}$ & 74.5 & $\mathrm{~d}$ & $3.48 \mathrm{~m}$ & 74.4 & $\mathrm{~d}$ \\
\hline $3^{\prime \prime \prime}$ & $3.42 \mathrm{~m}$ & 77.9 & $\mathrm{~d}$ & $3.46 \mathrm{~m}$ & 78.3 & $\mathrm{~d}$ & $3.48 \mathrm{~m}$ & 78.0 & $\mathrm{~d}$ \\
\hline $4^{\prime \prime \prime}$ & $3.36 \mathrm{~m}$ & 71.1 & $\mathrm{~d}$ & $3.40 \mathrm{~m}$ & 71.0 & $\mathrm{~d}$ & $3.36 \mathrm{~m}$ & 71.2 & $\mathrm{~d}$ \\
\hline $5^{\prime \prime \prime}$ & $3.52 \mathrm{~m}$ & 78.4 & d & $3.59 \mathrm{~m}$ & 76.9 & $\mathrm{~d}$ & $3.55 \mathrm{~m}$ & 78.4 & $\mathrm{~d}$ \\
\hline $6^{\prime \prime \prime} \mathrm{a}$ & $3.92 \mathrm{dd}(12.0,2.0)$ & 62.4 & $\mathrm{t}$ & $4.03 \mathrm{dd}(11.5,2.0)$ & 67.5 & $\mathrm{t}$ & $3.95 \mathrm{dd}(12.0,2.0)$ & 62.4 & $\mathrm{t}$ \\
\hline $6^{\prime \prime \prime} \mathrm{b}$ & $3.68 \mathrm{dd}(12.0,6.0)$ & & & $3.65 \mathrm{dd}(11.5,6.0)$ & & & $3.71 \mathrm{dd}(12.0,6.0)$ & & \\
\hline $1^{\prime \prime \prime \prime}$ & $4.84 \mathrm{~d}(7.5)$ & 102.1 & $\mathrm{~d}$ & $4.70 \mathrm{~d}(1.0)$ & 102.1 & $\mathrm{~d}$ & $4.85 \mathrm{~d}(7.5)$ & 102.1 & $\mathrm{~d}$ \\
\hline $2^{\prime \prime \prime \prime}$ & $3.42 \mathrm{~m}$ & 74.8 & d & $3.88 \mathrm{~m}$ & 71.8 & $\mathrm{~d}$ & $3.44 \mathrm{~m}$ & 74.6 & $\mathrm{~d}$ \\
\hline $3^{\prime \prime \prime \prime}$ & $3.44 \mathrm{~m}$ & 77.8 & $\mathrm{~d}$ & $3.69 \mathrm{dd}(9.5,3.5)$ & 72.0 & $\mathrm{~d}$ & $3.48 \mathrm{~m}$ & 78.0 & $\mathrm{~d}$ \\
\hline $4^{\prime \prime \prime \prime}$ & $3.38 \mathrm{~m}$ & 71.1 & $\mathrm{~d}$ & $3.33 \mathrm{~m}$ & 73.8 & $\mathrm{~d}$ & $3.44 \mathrm{~m}$ & 71.1 & $\mathrm{~d}$ \\
\hline $5^{\prime \prime \prime \prime}$ & $3.48 \mathrm{~m}$ & 78.5 & $\mathrm{~d}$ & $3.63 \mathrm{dd}(9.6,6.5)$ & 69.6 & $\mathrm{~d}$ & $3.39 \mathrm{~m}$ & 78.3 & $\mathrm{~d}$ \\
\hline $6^{\prime \prime \prime \prime} \mathrm{a}$ & $3.86 \mathrm{dd}(12.0,2.0)$ & 62.3 & $\mathrm{t}$ & $1.18 \mathrm{~d}(6.0)$ & 17.6 & $\mathrm{q}$ & $3.90 \mathrm{dd}(12.0,2.0)$ & 62.2 & $\mathrm{t}$ \\
\hline $6^{\prime \prime \prime \prime} \mathrm{b}$ & $3.68 \mathrm{dd}(12.0,6.0)$ & & & & & & $3.69 \mathrm{dd}(12.0,6.0)$ & & \\
\hline $4^{\prime \prime}-\mathrm{OCH}_{3}$ & $3.88 \mathrm{~s}$ & 56.0 & $q$ & & & & $3.88 \mathrm{~s}$ & 55.8 & $q$ \\
\hline
\end{tabular}

a Signal multiplicity and coupling constants $(\mathrm{Hz})$ are in given parentheses; the assignments were based on heteronuclear single quantum coherence (HSQC), HMBC, and ${ }^{1} \mathrm{H}_{-}{ }^{1} \mathrm{H}$ COSY experiments. 


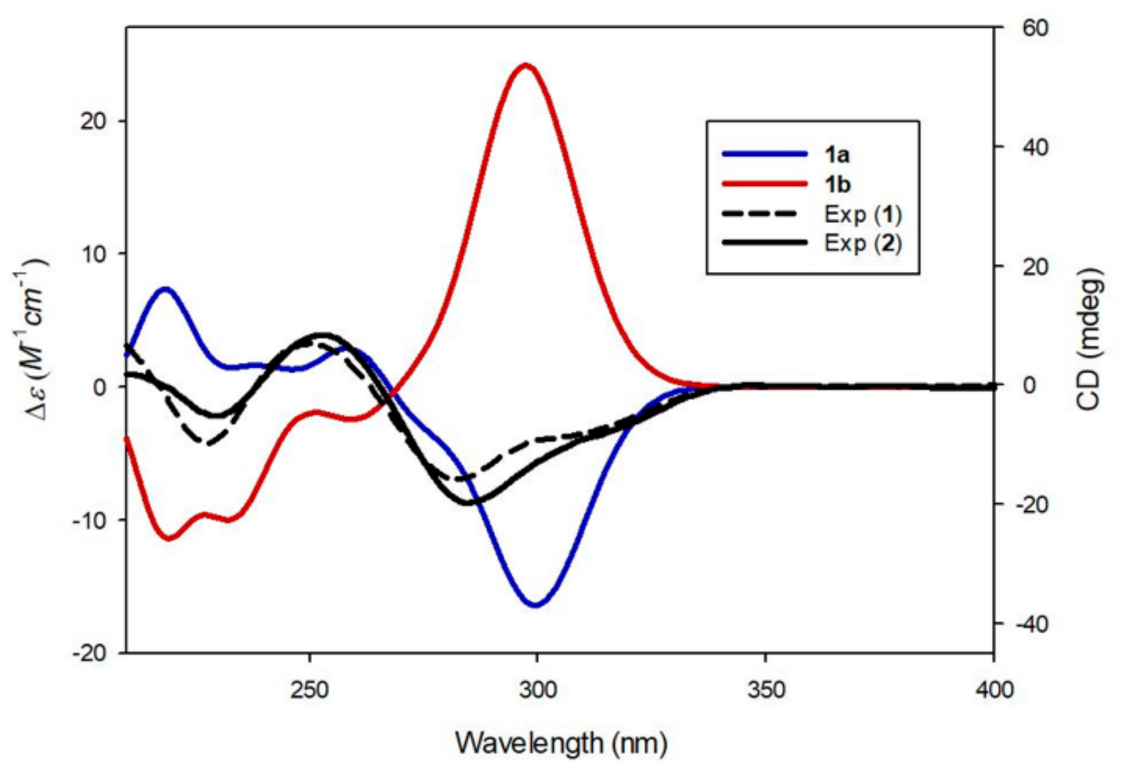

Figure 3. Experimental and calculated electronic circular dichroism (ECD) spectra of compounds 1 and 2.

Compound 2 was isolated as a white amorphous powder with a molecular formula of $\mathrm{C}_{29} \mathrm{H}_{34} \mathrm{O}_{14}$, as deduced from the HRESIMS data at $m / z 607.2018[\mathrm{M}+\mathrm{H}]^{+}$(calculated for $\mathrm{C}_{29} \mathrm{H}_{35} \mathrm{O}_{14}$ 607.2027) and NMR data (Table 1). The ${ }^{1} \mathrm{H}$ and ${ }^{13} \mathrm{C}$ NMR data of $\mathbf{2}$ showed signals quite similar to those of $\mathbf{1}$, with noticeable differences being the absence of signals for the methoxy group in $\mathbf{1}$ and the presence of an additional characteristic methyl group at $\delta_{\mathrm{H}} 1.18(3 \mathrm{H}, \mathrm{d}, J=6.0 \mathrm{~Hz}) / \delta_{\mathrm{C}} 17.6$. The characteristic methyl group was determined to be C- 6 of rhamnopyranose, and the two sugar moieties present in 2 were identified as rutinose [6-O- $\alpha$-rhamnosyl-( $1 \rightarrow 6)-\beta$-glucopyranoside] upon comparison with previously reported values [24] and analysis of the coupling constants of the anomeric proton signals at $\delta_{\mathrm{H}} 5.03(1 \mathrm{H}$, $\mathrm{d}, J=7.5 \mathrm{~Hz})$ and $4.70(1 \mathrm{H}, \mathrm{d}, J=1.0 \mathrm{~Hz})$. The complete planar structure of $\mathbf{1}$, including the position of the rutinosyl group, was determined by 2D NMR analysis $\left({ }^{1} \mathrm{H}-{ }^{1} \mathrm{H} C O S Y, \mathrm{HSQC}\right.$, and $\mathrm{HMBC}$ ) (Figure 2). The absolute configuration of 2 was determined via chemical reactions and quantum chemical ECD calculations. Acid hydrolysis of $\mathbf{2}$ yielded a glucopyranose and a rhamnopyranose, the absolute configurations of which were determined as D-glucopyranose and L-rhamnopyranose by LC/MS analysis of their thiocarbamoyl-thiazolidine derivatives. To establish the absolute configuration of C-4 in 2, computationally calculated ECD data of two enantiomers, $\mathbf{1 a}(4 R)$ and $\mathbf{1} \mathbf{b}(4 R)$, were compared with the experimental ECD data of $\mathbf{2}$ (Figure 3). The ECD data of $\mathbf{2}$ were well matched to the calculated ECD data of 1a and the experimental ECD data of $\mathbf{1}$. Collectively, these findings allowed the elucidation of the absolute structure of $\mathbf{2}$ as shown in Figure 1, and the compound was named lobatamunsolide B.

Compound 3 was isolated as a white amorphous powder, and its molecular formula was determined as $\mathrm{C}_{30} \mathrm{H}_{36} \mathrm{O}_{15}$ based on HRESIMS data at $\mathrm{m} / \mathrm{z} 637.2126[\mathrm{M}+\mathrm{H}]^{+}$(calculated for $\mathrm{C}_{30} \mathrm{H}_{37} \mathrm{O}_{15}$ 637.2132) and NMR data (Table 1). The ${ }^{1} \mathrm{H}$ and ${ }^{13} \mathrm{C}$ NMR spectra of 3 (Table 1) were almost identical to those of $\mathbf{1}$, with slight differences in the chemical shifts assigned to the butenolide moiety. Their superimposable NMR data and the fact that they have the same molecular formula suggested that compound $\mathbf{3}$ is a stereoisomer of $\mathbf{1}$. The complete structure of $\mathbf{3}$ was further confirmed by analysis of cross-peaks through $\mathrm{HMBC}$ and ${ }^{1} \mathrm{H}-{ }^{1} \mathrm{H}$ COSY experiments (Figure 4). Acid hydrolysis of 3 yielded a glucopyranose. The absolute configuration of this glucopyranose was established as $\mathrm{D}$-form through the LC/MS analysis of the thiocarbamoyl-thiazolidine derivatives of its acid hydrolysate. The ECD spectrum of 3 displayed opposite Cotton effects (247 (negative), 284 (positive) nm) to those of the ECD spectrum of $\mathbf{1}$, suggesting that the absolute configuration of C-4 in $\mathbf{3}$ is opposite to that of $\mathbf{1}$. Moreover, the experimental ECD data of $\mathbf{3}$ were in agreement with the calculated ECD data of $\mathbf{1 b}(4 S)$ rather than 
those of $1 \mathbf{a}(4 R)$ (Figure 5). Therefore, the absolute structure of 3 was determined as shown in Figure 1, and the compound was named lobatamunsolide $\mathrm{C}$.

The remaining six isolates from the $\mathrm{MeOH}$ extract of $P$. lobata roots were known compounds, which were identified as (+)-puerarol B-2-O-glucoside (4) [25], 3'-methoxydaidzin (5) [19], formononetin 8-C-apiofuranosyl-(1 $\rightarrow$ 6)-glucoside (6) [26], puerarin xyloside (7) [27], 3'-methoxypuerarin (8) [27], and daidzin (9) [27], by comparing their NMR spectroscopic data with those reported earlier and by LC/MS analysis.

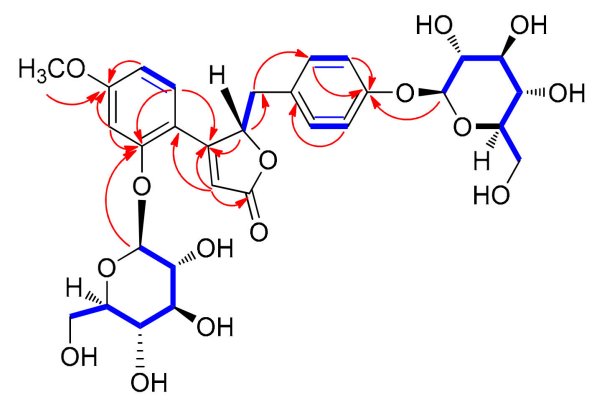

Figure 4. ${ }^{1} \mathrm{H}-{ }^{1} \mathrm{H}$ COSY (blue bold lines) and key HMBC correlations (red arrows) of 3.

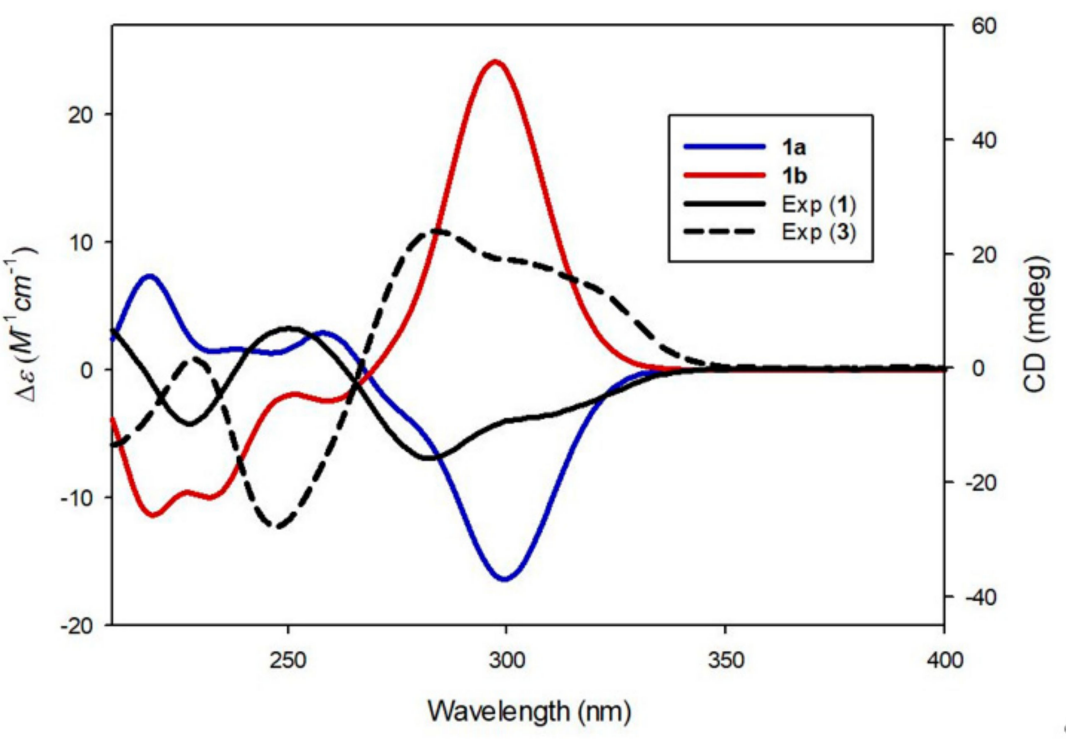

Figure 5. Experimental and calculated ECD spectra of compounds $\mathbf{1}$ and $\mathbf{3 .}$

\subsection{Inhibitory Effects of Compounds 1-6 on LPS-Induced NO Production in RAW 264.7 Cells}

Nitric oxide (NO) is known to have a close association with inflammation and possesses a dual regulatory function in the inflammatory reaction $[28,29]$. Under normal physiological conditions, NO plays anti-inflammatory roles; however, upon stimulation with LPS, inducible NO synthase (iNOS) is transcriptionally activated and, subsequently, NO is produced by macrophages as a first-line pro-inflammatory mediator. Excessive production of NO may lead to high expression of proinflammatory mediators and result in a variety of inflammatory diseases. Therefore, the discovery of agents that can inhibit excessive NO production might be an effective strategy to treat inflammatory disorders. Considering the goal to obtain NO inhibitors to treat inflammatory disorders and the traditional efficacy of $P$. lobate for this purpose, the inhibitory effects of compounds 1-9 isolated from P. lobate roots on NO production in LPS-stimulated RAW 264.7 macrophages were evaluated. Before evaluating the inhibitory activities, the effect of all compounds on cell viability at concentrations ranging from 3.125 to $100 \mu \mathrm{M}$ was tested using water-soluble tetrazolium, and no cytotoxic effects were observed (Figure 6A). NO assays were then carried out at the range of 6.25 to $100 \mu \mathrm{M}$. Compound 9 
exhibited the strongest $\mathrm{NO}$ inhibitory effect among all the isolated compounds, whereas compound 2 displayed a weak inhibitory effect on NO production in LPS-induced RAW 264.7 cells (Figure 6B).

\subsection{Molecular Docking Analysis of 9 and Its Inhibitory Effects on iNOS Expression}

To elucidate the possible mechanism through which compound 9 inhibits LPS-induced NO production, the mode of binding of compound 9 within the active site of iNOS was investigated. Compound 9 was subjected to molecular docking analysis using the published X-ray structure of iNOS complexed with a difluoroquinazoline inhibitor AR-C124355 ( $N$-[2-(4-Amino-5,8-difluoro-1,2-dihydroquinazolin-2-yl)ethyl]-3-furamide) [30]. The key interactions between AR-C124355 and amino acid residues in the active site of iNOS are as follows: (i) $\pi-\pi$ stacking between the diflorophenyl ring and heme cofactor, (ii) anchoring bidentate hydrogen bonds (H-bonds) between the cis-amidine moiety of difluoroquinazoline and the side chain carboxylate group of Glu371, and (iii) $\pi$-cation interaction between the furan moiety and guanidium group of Arg260 [30]. As shown in Figure 7A, compound 9 fits snugly into the binding pocket of AR-C124355 via heme stacking and H-bonding to Glu371. Upon looking at the docked pose of 9 in detail (Figure 7B,C), it can be seen that the phenol ring of the daidzein moiety is positioned in parallel with the porphyrin plane of heme to form a $\pi-\pi$ interaction, and that the three hydroxyl groups (C3, C5, and C6) of the D-glucopyranosyl moiety form H-bonds with Arg382, Asp376, and Glu371, respectively. The docking model suggests that 9 fits into the common binding pocket for known iNOS inhibitors, forming key interactions with Glu371 and the heme cofactor in the active site of iNOS, thus acting as an iNOS inhibitor.

To confirm whether the protein expression levels of iNOS were decreased by compound $\mathbf{9}$, western blotting experiments were performed. Corresponding to the results for the effects of compound 9 on NO production and its molecular docking with iNOS, compound 9 showed strong inhibition of the expression of iNOS protein in LPS-stimulated RAW 264.7 macrophages (Figure 8); however, compound 2 did not show such inhibitory effects.

(A)

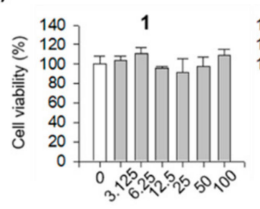

4

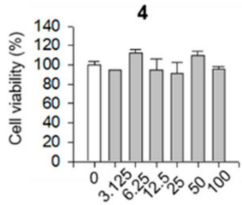

7

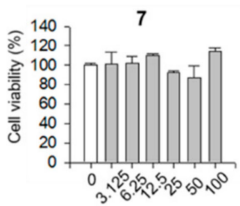

Cell viability
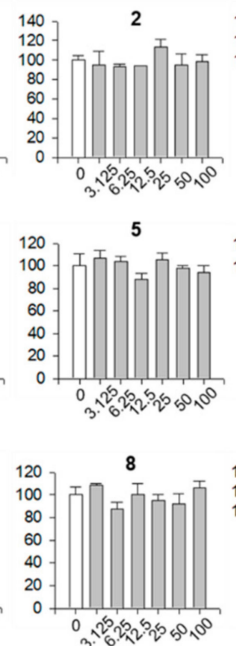

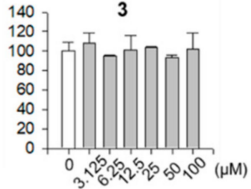

6
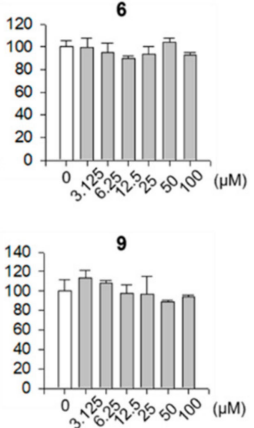

(B)
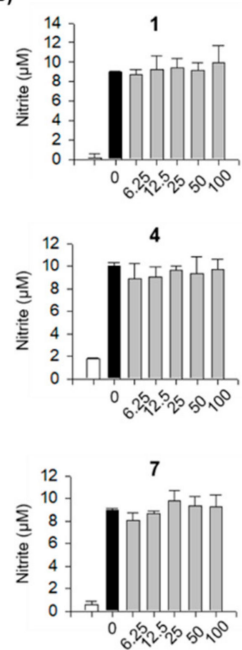

NO production
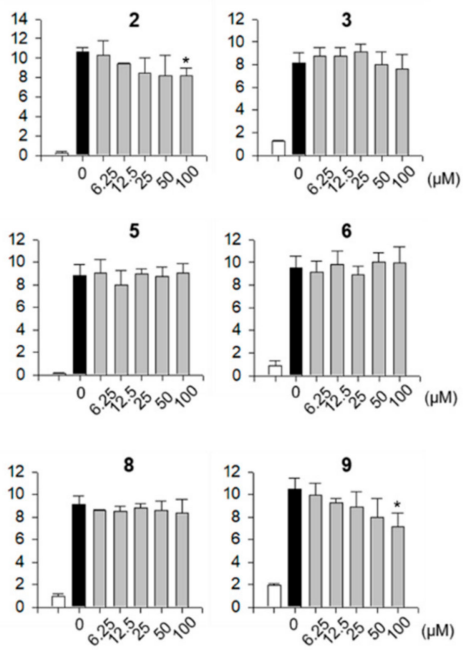

Figure 6. (A) Cell viabilities of the isolated compounds (1-9) measured using the EZ-Cytox cell viability assay. (B) Inhibitory effects of compounds 1-9 on LPS-induced NO production in RAW 264.7 cells. Cell viability data represent relative cell viability compared to that of the untreated group (100\%). $\mathrm{NO}$ assay data represent $\mathrm{NO}$ production levels calculated by applying absorbance values at $540 \mathrm{~nm}$ to a nitrite standard curve. $p<0.05$ relative to the LPS-treated control group. 


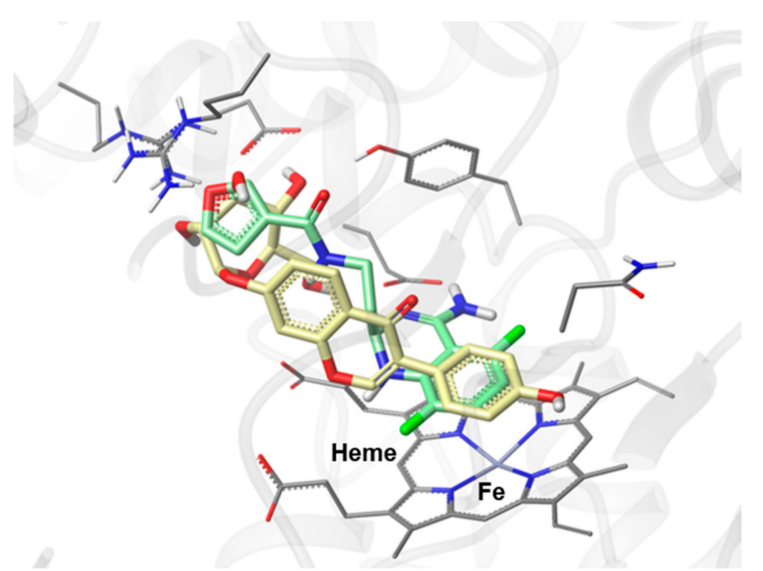

(A)

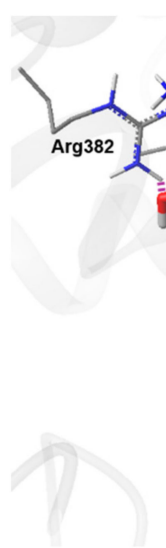

$+5$

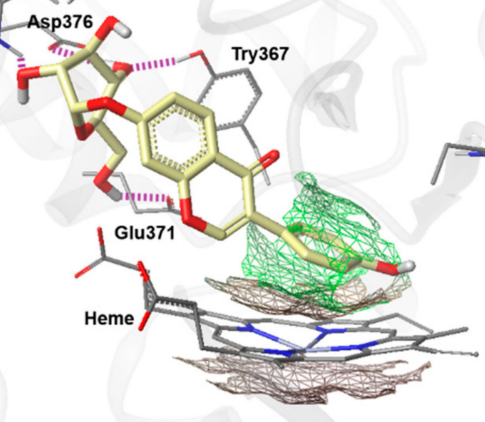

(B)

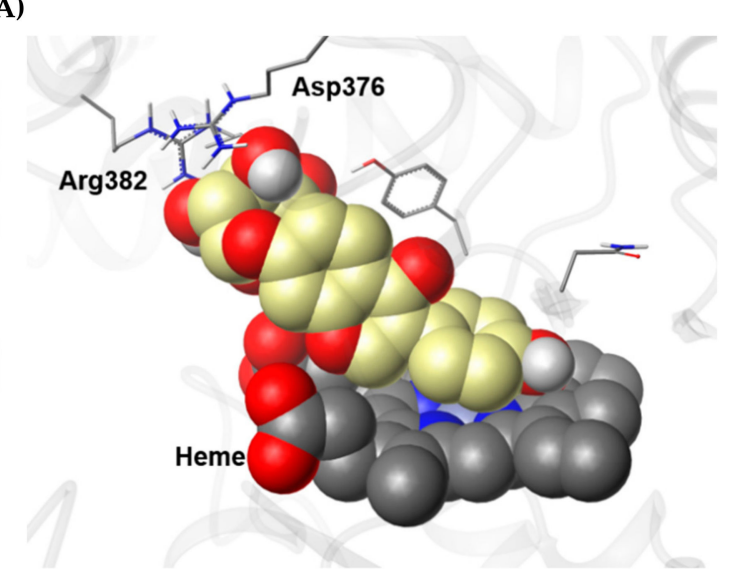

(C)

Figure 7. A putative binding mode of $\mathbf{9}$ in the active site of iNOS. (A) Superposition of the docked pose of 9 onto the co-crystalized pose of the inhibitor AR-C124355 in the active site of iNOS oxygenase (PDB id: 3E6O). The colors of the molecules are presented by atom type except for carbon atoms. The carbon atoms are colored green-blue (AR-C124355), yellow (9), and gray (amino acids); nitrogen is blue, oxygen is red, fluorine is green, hydrogen is white, and iron is light blue. (B) A docking pose of 9 fitted in the lipophilic domain. The amino acid residues involved in hydrogen bonds (H-bonds) are labeled and H-bonds are represented by purple dotted lines. The lipophilic potential surface, calculated by MOLCAD ${ }^{\mathrm{TM}}$ (a module in Sybyl-X 2.1.1), for heme and phenol moiety of 9 are stacked in parallel. (C) A view rendered in space-filling spheres, revealing a parallel stacking interaction between 9 and the co-factor heme. The atoms of docked $\mathbf{9}$ and heme are represented in Van der Waals spheres generated by Corey-Pauling-Koltun (CPK) rendering method.

iNOS expression

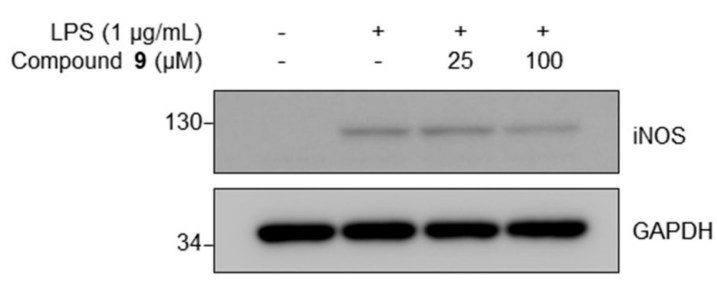

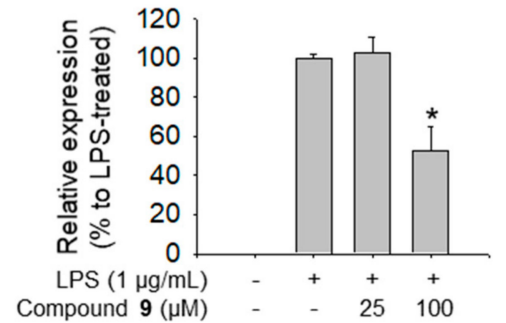

Figure 8. Inhibitory effects of compound 9 on LPS-induced iNOS expression in RAW 264.7 cells. Data represent relative iNOS protein expression levels compared to those in the LPS-treated group $(100 \%) . p<0.05$ relative to the LPS-treated control group. 


\section{Conclusions}

Phytochemical investigation of the $\mathrm{MeOH}$ extract of $P$. lobata roots combined with LC/MS-based analysis led to the discovery of four norlignans (1-4), including three new norlignans, lobatamunsolides A-C (1-3), and five known isoflavonoids (5-9). Their structures were established based on NMR spectroscopic data, chemical reactions, and quantum chemical ECD calculations. Compound 9 displayed significant NO inhibitory effect in LPS-stimulated RAW 264.7 macrophages. The potential mechanism of the effect was also investigated using molecular docking and western blot analyses, which showed that the mechanism of $\mathbf{9}$ was mediated by the inhibition of iNOS protein expression. Overall, the present findings suggest the potential of $P$. lobata roots for use as a functional food and medicine ingredient, and indicate that compound 9 could be a valuable compound for the development of promising anti-inflammatory agents.

Supplementary Materials: The following are available online at http://www.mdpi.com/2218-273X/9/12/755/s1, HR-ESIMS, and 1D and 2D NMR spectra of compounds 1-3, general experimental procedures, extraction and isolation, acid hydrolysis and determination of the absolute configuration of sugar moieties, and computational analysis are available free of charge on the Internet.

Author Contributions: Conceptualization, Y.-C.C., H.-J.P., and K.H.K.; formal analysis, M.S.J., J.S.Y., and S.L.; investigation, M.S.J., J.S.Y., J.C.L., and S.L.; data curation, M.S.J., S.L., Y.-C.C., H.-J.P., and K.H.K.; writing-original draft preparation, M.S.J., Y.-C.C., H.-J.P., and K.H.K.; writing-review and editing, M.S.J. and K.H.K.; supervision, Y.-C.C., H.-J.P., and K.H.K.; funding acquisition, K.H.K.

Funding: This work was supported by a National Research Foundation of Korea (NRF) grant funded by the Korea government (MSIT) (2018R1A2B2006879) and (2019R1A5A2027340). This research was supported by the Bio \& Medical Technology Development Program of the National Research Foundation of Korea (NRF) funded by the Korean government (MSIT) (NRF-2012M3A9C4048775).

Acknowledgments: We would like to thank Young Hye Kim (KBSI) for the ESIMS analysis.

Conflicts of Interest: The authors declare no conflict of interest.

\section{References}

1. Prasain, J.K.; Jones, K.; Kirk, M.; Wilson, L.; Smith-Johnson, M.; Weaver, C.; Barnes, S. Profiling and quantification of isoflavonoids in kudzu dietary supplements by high-performance liquid chromatography and electrospray ionization tandem mass spectrometry. J. Agric. Food Chem. 2018, 51, 4213-4218. [CrossRef] [PubMed]

2. Patterson, D.T. The history and distribution of five exotic weeds in North Carolina. Castanea 1976, 177-180.

3. Tanaka, T.; Tang, H.; Yu, F.; Michihara, S.; Uzawa, Y.; Zaima, N.; Moriyama, T.; Kawamura, Y. Kudzu (Pueraria lobata) vine ethanol extracts improve ovariectomy-induced bone loss in female mice. J. Agric. Food Chem. 2011, 59, 13230-13237. [CrossRef] [PubMed]

4. Tam, W.Y. The efficacy and tolerability of adjunctive alternative herbal medicine (Salvia miltiorrhiza and Pueraria lobata) on vascular function and structure in coronary patients. J. Altern. Complement. Med. 2009, 15, 415-421. [CrossRef] [PubMed]

5. Zhang, Z.; Lam, T.N.; Zuo, Z. Radix Puerariae: An overview of its chemistry, pharmacology, pharmacokinetics, and clinical use. J. Clin. Pharmacol. 2013, 53, 787-811. [CrossRef] [PubMed]

6. Jung, H.; Kang, A.N.; Kang, S.; Park, Y.K.; Song, M. The root extract of Pueraria lobata and its main compound, puerarin, prevent obesity by increasing the energy metabolism in skeletal muscle. Nutrients 2017, 9, 33. [CrossRef] [PubMed]

7. Bebrevska, L.; Foubert, K.; Hermans, N.; Chatterjee, S.; Van Marck, E.; De Meyer, G.; Vlietinck, A.; Pieters, L.; Apers, S. In vivo antioxidative activity of a quantified Pueraria lobata root extract. J. Ethnopharmacol. 2010, 127, 112-117. [CrossRef]

8. Reppert, A.; Yousef, G.G.; Rogers, R.B.; Lila, M.A. Isolation of radiolabeled isoflavones from kudzu (Pueraria lobata) root cultures. J. Agric. Food Chem. 2008, 56, 7860-7865. [CrossRef] 
9. Jin, S.E.; Son, Y.K.; Min, B.S.; Jung, H.A.; Choi, J.S. Anti-inflammatory and antioxidant activities of constituents isolated from Pueraria lobata roots. Arch. Pharm. Res. 2012, 35, 823-837. [CrossRef]

10. Keung, W.M.; Vallee, B.L. Kudzu root: An ancient Chinese source of modern antidipsotropic agents. Phytochemistry 1998, 47, 499-506. [CrossRef]

11. Kayano, S.I.; Matsumura, Y.; Kitagawa, Y.; Kobayashi, M.; Nagayama, A.; Kawabata, N.; Kikuzaki, H.; Kitada, Y. Isoflavone C-glycosides isolated from the root of kudzu (Pueraria lobata) and their estrogenic activities. Food Chem. 2012, 134, 282-287. [CrossRef]

12. Zhou, Y.-X.; Zhang, H.; Peng, C. Puerarin: A review of pharmacological effects. Phytother. Res. 2014, 28, 961-975. [CrossRef] [PubMed]

13. Yu, J.S.; Lee, D.; Lee, S.R.; Lee, J.W.; Choi, C.-I.; Jang, T.S.; Kang, K.S.; Kim, K.H. Chemical characterization of cytotoxic indole acetic acid derivative from Mulberry fruit (Morus alba L.) against human cervical cancer. Bioorg. Chem. 2018, 76, 28-36. [CrossRef] [PubMed]

14. So, H.M.; Eom, H.J.; Lee, D.; Kim, S.; Kang, K.S.; Lee, I.K.; Baek, K.-H.; Park, J.Y.; Kim, K.H. Bioactivity evaluations of betulin identified from the bark of Betula platyphylla var. japonica for cancer therapy. Arch. Pharm. Res. 2018, 41, 815-822. [PubMed]

15. Yu, J.S.; Roh, H.-S.; Baek, K.-H.; Lee, S.; Kim, S.; So, H.M.; Moon, E.; Pang, C.; Jang, T.S.; Kim, K.H. Bioactivity-guided isolation of ginsenosides from Korean Red Ginseng with cytotoxic activity against human lung adenocarcinoma cells. J. Ginseng Res. 2018, 42, 562-570. [CrossRef] [PubMed]

16. Lee, S.R.; Song, J.H.; Song, J.-H.; Ko, H.-J.; Baek, J.Y.; Trinh, T.A.; Beemelmanns, C.; Yamabe, N.; Kim, K.H. Chemical identification of isoflavonoids from a termite-associated Streptomyces sp. RB1 and their neuroprotective effects in murine hippocampal HT22 cell line. Int. J. Mol. Sci. 2018, 19, 2640. [CrossRef]

17. Baek, S.C.; Choi, E.; Eom, H.J.; Jo, M.S.; Kim, S.; So, H.M.; Kim, S.H.; Kang, K.S.; Kim, K.H. LC/MS-based analysis of bioactive compounds from the bark of Betula platyphylla var. japonica and their effects on regulation of adipocyte and osteoblast differentiation. Nat. Prod. Sci. 2018, 24, 235-240.

18. Ahn, S.-Y.; Jo, M.S.; Lee, D.; Baek, S.-E.; Baek, J.; Yu, J.S.; Jo, J.; Yun, H.; Kang, K.S.; Yoo, J.-E.; et al. Dual effects of isoflavonoids from Pueraria lobata roots on estrogenic activity and anti-proliferation of MCF-7 human breast carcinoma cells. Bioorg. Chem. 2019, 83, 135-144. [CrossRef]

19. Hirakura, K.; Morita, M.; Nakajima, K.; Sugama, K.; Takagi, K.; Niitsu, K.; Ikeya, Y.; Maruno, M.; Okada, M. Phenolic glucosides from the root of Pueraria lobata. Phytochemistry 1997, 46, 921-928. [CrossRef]

20. Coxon, B. Two-dimensional J.-resolved proton nuclear magnetic resonance spectrometry of hydroxyl-coupled $\alpha$ - and $\beta$-D-glucose. Anal. Chem. 1983, 55, 2361-2366. [CrossRef]

21. Tanaka, T.; Nakashima, T.; Ueda, T.; Tomii, K.; Kouno, I. Facile discrimination of aldose enantiomers by reversed-phase HPLC. Chem. Pharm. Bull. 2007, 55, 899-901. [CrossRef] [PubMed]

22. Muhit, M.A.; Umehara, K.; Mori-Yasumoto, K.; Noguchi, H. Furofuran lignan glucosides with estrogen-inhibitory properties from the Bangladeshi medicinal plant Terminalia citrina. J. Nat. Prod. 2016, 79, 1298-1307. [CrossRef] [PubMed]

23. Kil, Y.S.; Kim, S.M.; Kang, U.; Chung, H.Y.; Seo, E.K. Peroxynitrite-scavenging glycosides from the stem bark of Catalpa ovata. J. Nat. Prod. 2017, 80, 2240-2251. [CrossRef] [PubMed]

24. Aquino, R.; Behar, I.; D'agostino, M.; Simone, F.D.; Schettino, O.; Pizza, C. Phytochemical investigation on Mercurialis annua. Biochem. Syst. Ecol. 1987, 15, 667-669. [CrossRef]

25. Ding, H.Y.; Chen, Y.P.; Chang, W.L.; Lin, H.C. Isoflavonoids and but-2-enolides from the roots of Pueraria lobata. Chin. Pharm. J. 2004, 56, 31-35.

26. Wang, F.R.; Ge, X.Z.; Yang, X.W. Chemical constituents of Tongmai formula. Chin. J. Exp. Tradit. Med. Formulae 2011, 17, 61-69.

27. Kinjo, J.E.; Furusawa, J.I.; Baba, J.; Takeshita, T.; Yamasaki, M.; Nohara, T. Studies on the constituents of Pueraria lobata. III. Isoflavonoids and related compounds in the roots and the voluble stems. Chem. Pharm. Bull. 1987, 35, 4846-4850. [CrossRef]

28. Lee, S.; Lee, D.; Lee, J.C.; Kang, K.S.; Ryoo, R.; Park, H.J.; Kim, K.H. Bioactivity-guided Isolation of Anti-inflammatory Constituents of the Rare Mushroom Calvatia nipponica in LPS-stimulated RAW264.7 Macrophages. Chem. Biodivers. 2018, 15, e1800203. [CrossRef] 
29. Lee, S.; Lee, D.; Lee, S.O.; Ryu, J.Y.; Choi, S.Z.; Kang, K.S.; Kim, K.H. Anti-inflammatory activity of the sclerotia of edible fungus, Poria cocos Wolf and their active lanostane triterpenoids. J. Funct. Foods 2017, 32, 27-36. [CrossRef]

30. Garcin, E.D.; Arvai, A.S.; Rosenfeld, R.J.; Kroeger, M.D.; Crane, B.R.; Andersson, G.; Andrews, G.; Hamley, P.J.; Mallinder, P.R.; Nicholls, D.J.; et al. Anchored plasticity opens doors for selective inhibitor design in nitric oxide synthase. Nat. Chem. Biol. 2008, 4, 700-707. 